\title{
How do polyethylene glycol and poly(sulfobetaine) hydrogel layers on ultrafiltration membranes minimize fouling and stay stable in cleaning chemicals?
}

\author{
Ngoc Lieu Le ${ }^{1}$, Mathias Ulbricht ${ }^{2 *}$, Suzana P. Nunes ${ }^{1 *}$ \\ ${ }^{1}$ King Abdullah University of Science and Technology (KAUST), \\ Biological and Environmental Science and Engineering Division (BESE), \\ Thuwal, 23955-6900, Saudi Arabia \\ ${ }^{2}$ Lehrstuhl für Technische Chemie II, Universität Duisburg-Essen, 45117 Essen, Germany \\ *Corresponding authors: \\ Mathias Ulbricht \\ Email address: mathias.ulbricht@uni-essen.de \\ Tel.: +492011833151 \\ Suzana Nunes \\ Email address: suzana.nunes@kaust.edu.sa
}

Tel.: +966544700052 


\begin{abstract}
We compare the efficiency of grafting polyethylene glycol (PEG) and poly(sulfobetaine) hydrogel layer on polyetherimide (PEI) hollow-fiber ultrafiltration membrane surfaces in terms of filtration performance, fouling minimization and stability in cleaning solutions. Two previously established different methods toward the two different chemistries (and both had already proven to be suited to reduce fouling significantly) are applied to the same PEI membranes. The hydrophilicity of PEI membranes is improved by the modification, as indicated by the change of contact angle value from $89^{\circ}$ to $68^{\circ}$ for both methods, due to the hydration layer formed in the hydrogel layers. Their pure water flux declines because of the additional permeation barrier from the hydrogel layers. However, these barriers increase protein rejection. In the exposure at a static condition, grafting PEG or poly(sulfobetaine) reduces protein adsorption to $23 \%$ or $11 \%$, respectively. In the dynamic filtration, the hydrogel layers minimizes the flux reduction and increases the reversibility of fouling. Compared to the pristine PEI membrane that can recover its flux to $42 \%$ after hydraulic cleaning, the PEG and poly(sulfobetaine) grafted membranes can recover their flux up to $63 \%$ and $94 \%$, respectively. Stability tests show that the poly(sulfobetaine) hydrogel layer is stable in acid, base and chlorine solutions, while the PEG hydrogel layer suffers alkaline hydrolysis in base and oxidation in chlorine conditions. With its chemical stability and pronounced capability of minimizing fouling, especially irreversible fouling, protective poly(sulfobetaine) hydrogel layers have great potential for various membrane-based applications.
\end{abstract}

Keywords: polyethylene glycol, poly(sulfobetaine), zwitterionic, ultrafiltration membrane, reversible fouling, stability, chlorine. 


\section{Introduction}

Membrane fouling has attracted more and more attention because it significantly reduces the performance of membrane processes. In ultrafiltration, typical foulants are proteins ${ }^{1}$, polysaccharides $^{2}$ and humic substances ${ }^{3}$. To minimize this organic fouling, membrane surface characteristics such as hydrophilicity, charge and roughness have been modified ${ }^{4-6}$. These modifications can be efficiently conducted by grafting hydrogels on the surface ${ }^{7}$ Hydrogels are three-dimensional (3D) macromolecular network architectures, which are insoluble in water but able to absorb large amounts of water and swell. The generated hydration layer plays a crucial role as a barrier to prevent protein molecules from direct contact with the solid membrane surface. Jeon et al. $^{8}$ reported that the approach of protein molecules towards the hydrogelgrafting surface causes the compression of the hydrogel leading to repulsive elastic forces. Along with the osmotic stress produced by the release of water molecules from the hydrated hydrogel during compression, such layers create an unfavorable repulsive force on protein molecules. Besides swelling, softness and hydrophilicity, three of the distinguishing characteristics of hydrogels, the interactions between their specific chemistry and the foulants must also be considered. In general, wettability (or the surface interaction with water), presence of hydrogen bond acceptors, absence of hydrogen bond donors and charge neutrality are essential properties of hydrogel chemistry for its efficient resistance to protein adsorption ${ }^{9-10}$. Poly(ethylene glycol) (PEG) with mentioned favorable features has been extensively studied to minimize membrane fouling. Its bioinert property including nontoxicity is another advantage. When long-chained PEGs are used, their steric repulsion effect can play an additional role. Jeon and Andrade ${ }^{11}$ found that the fouling resistance would increase with the chain length of PEGs for a given surface density of the polymer. In addition, the conformation of PEG-based segments in their self- 
assembled monolayers also affects fouling behavior. For example, Grunze et al. ${ }^{12}$ reported that the helical conformation tuned the surface to become inert to protein absorption while the trans conformation had no significant effect. Preparation of PEG-modified surfaces can be based on physical or chemical adsorption, direct covalent binding, and block or graft copolymerization ${ }^{13}$. Regardless to modification techniques, however, PEG-based surfaces face with disputable longterm stability because they have been reported to be susceptible to oxidative damage in the presence of oxygen and transition metal ions ${ }^{12,14-16}$.

The development of surface-initiated controlled radical polymerization allows membrane surfaces to be modified with a well-defined structure of highly dense polymers with tunable chain length. With this advanced technique, many hydrophilic polymers such as poly(vinyl

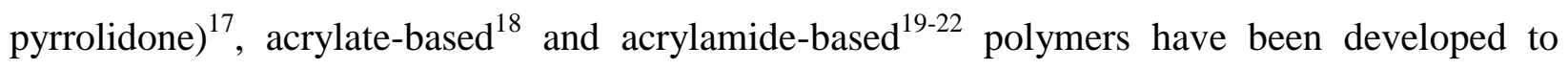
reduce fouling. Zwitterionic polymers are of interest because of their high wettability and neutral charge. Compared to PEGs, their fouling resistance is considered superior because they can produce a much stronger surface hydration layer by ionic solvation of their zwitterionic groups ${ }^{23-}$ 25. Besides the balanced charge, another key factor that affects the electrostatic interaction between zwitterionic groups and water molecules is the minimized dipole of zwitterions, which can be achieved if their structure and spacer chain length between cationic and aninic groups are well-defined $^{26}$. Moreover, high density of the zwitterionic polymer chains also plays an important role in their nonfouling propensity ${ }^{27-29}$. In recent years, taking the advantage of surface-initiated radical polymerization, zwitterionic polymers with a well-defined structure have been directly grafted on metallic and inorganic substrates such as gold ${ }^{30-31}$, glass ${ }^{32-33}$ and silicon wafers $^{34}$ as well as on porous membrane substrates ${ }^{27-29,35}$ to exhibit their nonfouling properties. 
Particularly, the efficiency of polyzwitterion grafted membranes in preventing protein fouling have been extensively demonstrated ${ }^{36-47}$.

Here we conducted a systematic and comprehensive comparison of PEG and polyzwitterion hydrogel layer grafting on ultrafiltration membranes. We used two previously established methods which had already been demonstrated to be very well applicable to ultrafiltration membranes leading to promising overall performance improvement (cf. Figure 1). PEG layers were grafted by adopting the method for membrane modification introduced by the Freeman group $^{48-49}$, i.e. first depositing a thin polydopamine interlayer and second chemically grafting PEG chains to that layer. Polyzwitterion layer were also obtained in a two-step approach ${ }^{28-29}$, i.e. first adsorbing a macroinitiator and thereafter conducting a surface-initiated cross-linking copolymerization. Along with their nonfouling propensity, their effects on filtration properties of membranes in terms of water permeability and protein rejection as well as their long-term stability in cleaning chemicals, a crucial criterion for pratical applications, were in-depth analyzed. Laboratory-made polyetherimide (PEI) hollow fibers membranes with a well-defined structure for ultrafiltration applications were used as the substrate.

a)

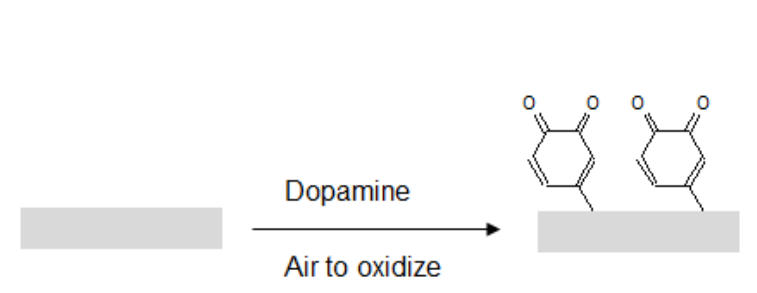

b)

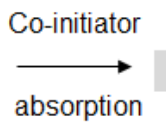

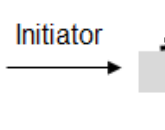

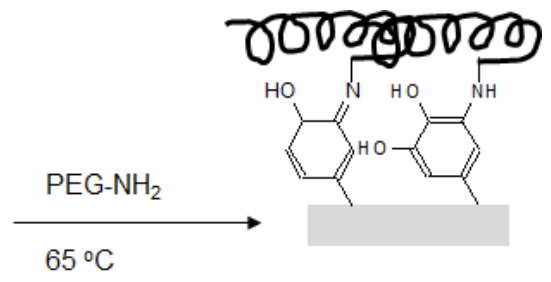

On-surface free radical
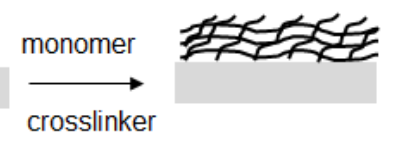

Figure 1. Schematic procedures of (a) PEG and (b) polyzwitterion grafting. 


\section{Experimental}

\subsection{Materials}

Polyetherimide (PEI) Ultem ${ }^{\circledR} 1000$, provided by Sabic (Saudi Arabia), diethylene glycol (DEG, 99\%, Alfa-Aesar) and N-methyl-2-pyrrolidinone (NMP, $\geq 99.5 \%$, Merck) were used to prepare the dope solution for the fabrication of hollow fiber substrate membranes. Ethylene glycol (EG, 99.8\%, Sigma-Aldrich) was used as bore fluid for hollow fiber membrane spinning.

Dopamine hydrochloride (Sigma-Aldrich), Tris hydrochloride (UltraPure ${ }^{\mathrm{TM}}$, Invitrogen), ethanol (Sigma-Aldrich) and methoxypolyethylene glycol amine ( $\left.\mathrm{NH}_{2}-\mathrm{PEG}\right)$ (5,000 Da, Sigma-Aldrich) were used for PEG grafting. Tris buffer $(15 \mathrm{mM})$ was prepared by dissolving Tris $\mathrm{HCl}$ (2.634 $\mathrm{g} / \mathrm{L}$ ) in Milli-Q water and adjusting the $\mathrm{pH}$ of the resultant solution to 8.8 using sodium hydroxide (Sigma-Aldrich).

The zwitterionic monomer 3-((3-methacrylamidopropyl)dimethylammonio)propane-1-sulfonate (SPP) was synthesized in our laboratory from 1,3-propanesultone and N-[3(dimethylamino)propyl]methacrylamide (Sigma-Aldrich). The macromolecular redox coinitiator, poly((2-dimethylamino)ethyl methacrylate-co-butyl methacrylate) (poly(DMAEMAco-BMA)) was also self synthesized as reported before ${ }^{29}$ from 2(dimethylamino)ethylmethacrylate (DMAEMA, $98 \%$ ), butylmethacrylate (BMA, $99 \%$ ) and 2,2'-azobis(2-methylpropionitrile (AIBN, $98 \%$ ) which were also all from Sigma-Aldrich. Other chemicals for surface-initiated radical polymerization including N,N-methylene bisacrylamide (MBAA), ammonium persulfate (APS) and isopropanol were also obtained from Sigma-Aldrich. Figure 2 shows the chemical structures of PEI, SPP, MBAA and $\mathrm{NH}_{2}$-PEG. 
a)<smiles>Cc1ccc(N2C(=O)c3ccc(Oc4ccc(C(C)(C)c5ccc(Oc6ccc7c(c6)C(=O)N(C)C7=O)cc5)cc4)cc3C2=O)cc1</smiles>

b)<smiles>C=C(C)C(=O)NCCC[N+](C)(C)CCCS(=O)(=O)[O-]</smiles>

c)<smiles>C=CC(=O)NCNC(=O)C=C</smiles><smiles>CC(C)(C)OCCC(C)(C)OCCN</smiles>

Figure 2. Chemical structures of (a) PEI, (b) SPP, (c) MBAA and (d) $\mathrm{NH}_{2}$-PEG.

$\gamma$-Globulin from bovine blood ( $\geq 99 \%$ ), bovine serum albumin (BSA, $\geq 96 \%$ ) and myoglobin from equine skeletal muscle (95-100\%) for protein rejection tests were obtained from SigmaAldrich. Their molecular weights and isoelectric points (pIs) are presented in Table 1S. The fluorescein isothiocyanate-conjugated bovine serum albumin (BSA-FITC) from Sigma-Aldrich was used for static protein fouling tests.

Hydrochloric acid ( 37 \%, Alfa Aesar), sodium hydroxide (Sigma-Aldrich) and sodium hypochlorite (10-15\%, Sigma-Aldrich) were used to prepare cleaning solutions.

\subsection{Membrane fabrication}

PEI hollow fiber membranes were fabricated through a non-solvent-induced phase inversion process using a dry-jet wet spinning line as described elsewhere ${ }^{50}$. The detailed spinning conditions are listed in Table $2 \mathrm{~S}$. For some characterizations, the flat-sheet membranes with the analogous top surface structure (as shown in Supporting Information) were prepared by casting 
the same dope solution on a glass plate with a casting knife gap of $200 \mu \mathrm{m}$ and then immediately immersing the plate into a water bath, changing water several times and keeping the membranes in water before tests. The membrane modules were prepared with 2-3 fibers per module and their effective length was around $13.4 \mathrm{~cm}$.

\subsection{Grafting PEG and polyzwitterionic layers on membrane surfaces}

To attach PEG on the membrane surface, PEG terminated with an amine group was anchored onto the previously dopamine-coated membrane surface; the method is analogous to work in literature $^{48-49}$ (cf. Figure 1). Zwitterionic polysulfobetaine was grafted onto the membrane surface by our environmentally friendly surface-initiated radical polymerization technique where a sticky macromolecular co-initiator with a capability of accelerating the decomposition of a water-soluble redox initiator is first absorbed on the membrane surface. A detailed function of the macro-initiator and grafting mechanism of the polysulfobetaine can be found in our previous studies $^{28-29}$ (cf. Figure 1).

Before the attachment of PEG, wet hollow fibers in an assembled module were circulated with a dopamine solution $(80 \mathrm{mg} / \mathrm{mL}$ in Tris buffer) with the flow rate of $4 \mathrm{ml} / \mathrm{min}$ using a cartridge pump (Thermo Scientific) for $1 \mathrm{~h}$ in an open condition. The module was then soaked in ethanol for $10 \mathrm{~min}$ and rinsed in Milli-Q water for $30 \mathrm{~min}$ to remove unreacted dopamine. The module was subsequently filled with a $\mathrm{NH}_{2}$-PEG solution $(1 \mathrm{~g} / \mathrm{L}$ in Tris buffer $)$ and kept at $65{ }^{\circ} \mathrm{C}$ in an oven for $1 \mathrm{~h}$ for the reaction between amine groups of $\mathrm{NH}_{2}$-PEG and ketone groups of oxidized dopamine to form either imine or secondary amine bonds (cf. Figure 1). This temperature may also promote the chemical interaction between the amine group of dopamine and the imide rings of PEI and strengthen the adhesion between the grafting layer and the membrane substrate. After 
that, the module was rinsed with Milli-Q water to remove unreacted $\mathrm{NH}_{2}-\mathrm{PEG}$ molecules. The module was stored in a water-containing zip bag in a fridge at $4{ }^{\circ} \mathrm{C}$.

Polyzwitterion grafting procedure started with the circulation of n-propanol through the membrane module and then stabilizing it in water for $1 \mathrm{~h}$. After that, the macromolecular coinitiator solution ( $1 \mathrm{~g} / \mathrm{L}$ in water/isopropanol 8:2) was pumped through the module for 5 min and the module was then rinsed with water for $1 \mathrm{~h}$. The module was subsequently circulated with the degased solution of SPP $(0.25 \mathrm{M})$, MBAA $(6 \mathrm{wt} \%)$ and APS $(2.25 \mathrm{~g} / \mathrm{l})$ for $2 \mathrm{~h}$ at a closed condition and then rinsed with Milli-Q water and kept in a fridge.

Analogous protocols were used to graft PEG and polyzwitterion layers on flat-sheet membranes $(2 \mathrm{~cm} \times 2 \mathrm{~cm})$, but instead of flushing, they were just immersed into the solutions. The flat-sheet membranes were chosen for characterizations by Fourier Transform Infrared Spectroscopy (FTIR) and fluorescein microscopy, instead of hollow fibers, because flat surfaces provide more reliable results.

\subsection{Characterizations of hollow fiber membranes}

The hollow fiber membrane morphology was analyzed by a field emission scanning electron microscope (FESEM, Quanta 200 or Nova Nano). Before observation, the membranes were fractured in liquid nitrogen and then coated with iridium using a sputter coater.

The contact angles of hollow fiber membranes before and after grafting were measured by a Sigma 701 Tensiometer from KSV Instruments Limited. The hollow fibers were sealed at their one end and then immersed into distilled water. Their receding contact angles were calculated with the aid of a computer software. The obtained results are average values of five readings. 
The chemical structures of the unmodified and modified flat-sheet membranes were characterized using Fourier transform infrared spectroscopy (FTIR) (is ${ }^{\mathrm{TM}} 10$, ThermoFisher) over the range of $1000-4000 \mathrm{~cm}^{-1}$ in the attenuated total reflectance (ATR) mode using the crystal type of diamond with $\mathrm{ZnSe}$ lens. The spectra were obtained with an average of 16 scans with a resolution of $1 \mathrm{~cm}^{-1}$. The depth of penetration $\left(d_{p}\right)$ of the IR beam into the sample is defined as below:

$$
d_{p}=\frac{\lambda}{2 \pi n_{1} \sqrt{\sin ^{2} \theta-\left(\frac{n_{2}}{n_{1}}\right)^{2}}}
$$

where $\lambda$ is the wavelength of light, $\theta$ is the angle of incidence of the IR beam, $n_{1}$ and $n_{2}$ are the refractive indices of the crystal and sample, respectively. Using the crystal type of diamond with ZnSe lens, $n_{1}=2.4$ and $\theta=42^{\circ}$. The $n_{2}$ value of 1.5 is chosen for general organic compounds.

\subsection{Filtration tests}

The pure water permeance, $P W P\left(\mathrm{Lm}^{-2} \mathrm{bar}^{-1} \mathrm{~h}^{-1}\right)$, was measured by circulating water in the module at a constant flow rate of $0.1 \mathrm{Lmin}^{-1}$ under a pressure of 1 bar and then calculated using the equation:

$$
P W P=\frac{Q}{\Delta P \times A_{m}}
$$

where $Q$ is the water permeation volumetric flow rate $(\mathrm{L} / \mathrm{h}), A_{m}$ is the effective area $\left(\mathrm{m}^{2}\right)$, and $\Delta P$ is the transmembrane pressure (bar).

Protein rejection $(R)$ was measured by circulating $1 \mathrm{~g} / \mathrm{L}$ protein solutions through the module. Their rejection was calculated based on their permeate and feed concentrations, which were 
analyzed by a UV spectrometer at $280 \mathrm{~nm}$ (Thermo Scientific, Nanodrop 2000c), using the equation below:

$$
R(\%)=\left(1-\frac{c_{p}}{c_{f}}\right)
$$

where $c_{p}$ and $c_{f}$ are the protein concentrations in the permeate and feed solution, respectively.

\subsection{Fouling tests}

To evaluate protein adsorption, fluorescein isothiocyanate-conjugated bovine serum albumin (BSA-FITC) was used. The flat-sheet membranes were initially immersed in a phosphatebuffered saline solution and then in a BSA-FITC solution $(0.5 \mathrm{mg} / \mathrm{ml})$ at room temperature for 1

h. The adsorbed protein was imaged using an Olympus BX41 microscope. The surface density of the adsorbed fluorescein-labelled protein was determined through calculating the fluorescence intensity on the membrane surface using ImageJ software (National Institutes of Health, Bethesda, MD).

Fouling tests were carried out by circulating the module with a $500 \mathrm{ppm} \gamma$-globulin solution until the flux was unchanged. The relative flux reduction $(F R)(\%)$ was calculated by the following equation:

$$
F R(\%)=1-\frac{J_{p}}{J_{w}}
$$

where $J_{p}$ and $J_{w}$ are the fluxes measured for protein solution and pure water, respectively. After that, the module was rinsed with water for $2 \mathrm{~h}$ and the pure water flux was re-measured $\left(J_{w 2}\right)$. The flux recovery ratio $(F R R)(\%)$ was calculated by the following equation:

$$
\operatorname{FRR}(\%)=\frac{J_{w 2}}{J_{w}}
$$


The relative flux enhancement $(F E)(\%)$ of the modified membranes in comparison with the unmodified membrane, all after fouling tests, was calculated by the following equation:

$$
F E(\%)=\frac{J_{m}}{J_{u m}}-1
$$

where $J_{m}$ and $J_{u m}$ are the fluxes of the modified and unmodified membranes, respectively, measured for pure water after operation with the fouling tests and washing step.

\subsection{Stability}

The modules with unmodified and modified membranes were filled with sodium hydroxide solution at $\mathrm{pH} \sim 12$, hydrochloric acid solution at $\mathrm{pH} \sim 2$, or sodium hypochlorite solution with an active chlorine concentration of $\sim 500 \mathrm{mg} / \mathrm{L}$. The modules were taken out after particular intervals of time, rinsed with water, and characterized for pure water flux. After measurement, the modules were filled again with the chemical solutions. Similarly, the flat-sheet membranes were also immersed into these solutions and then used for FTIR analyses after the period of 6day tests.

\section{Results and discussion}

\subsection{PEI hollow fiber membranes}

Figure 3 illustrates the PEI hollow fiber substrate membrane morphology, which consists of two layers of finger-like macrovoids surrounded by sponge-like porous substructures. These largesized macrovoids act as the transport channel for water permeation, while the porous substructures provide the mechanical strength for the fiber. The outer surface or selective layer has pores of $8.6 \pm 1.7 \mathrm{~nm}$, which would be able to retain molecules of $67 \mathrm{kDa}$. Poly(ethylene glycol) and poly(ethylene oxide) with different molecular weights were used for solute rejection 
tests. Detailed calculations for molecular weight cut-off (MWCO) and pore size can be found elsewhere ${ }^{51}$.
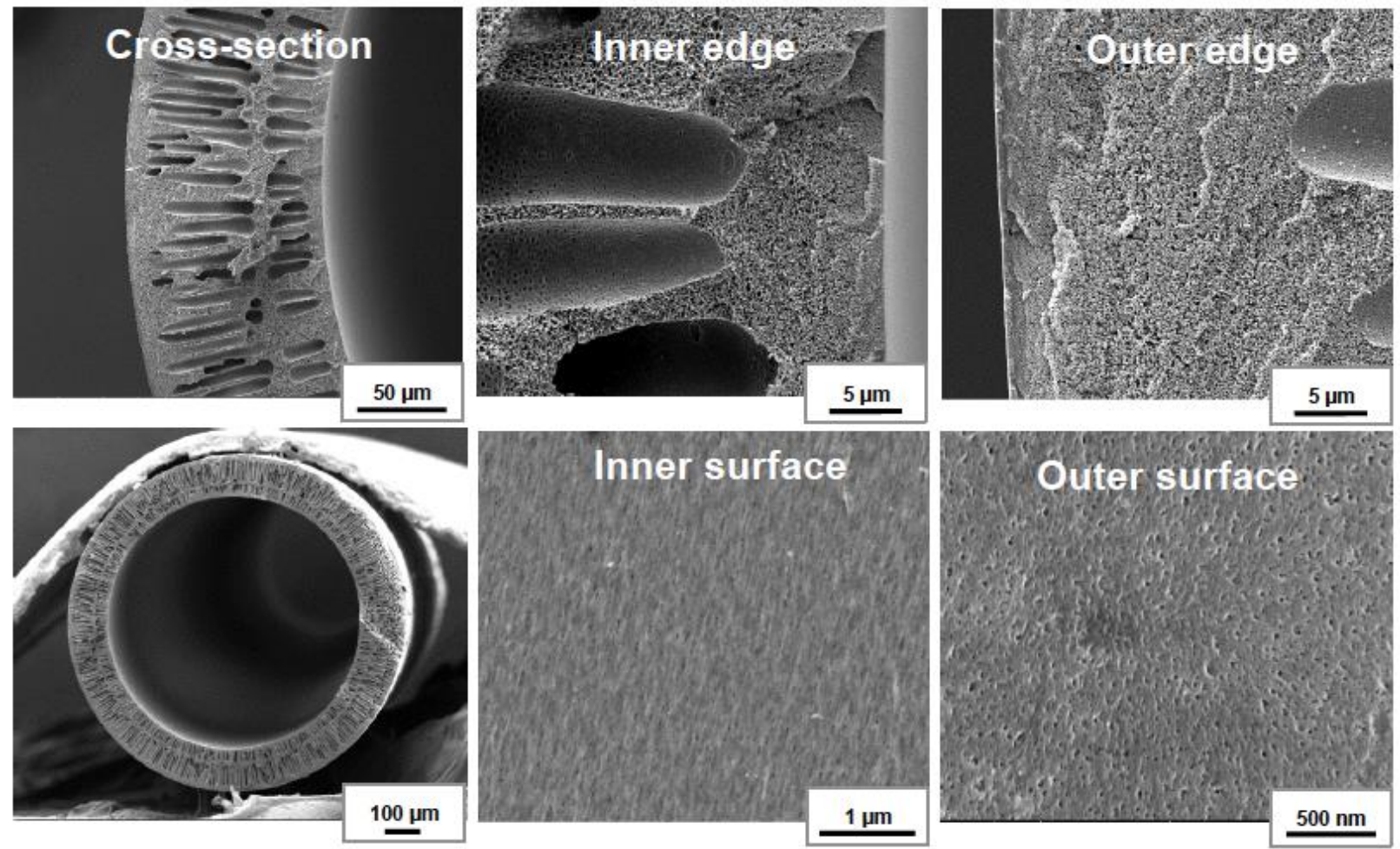

Figure 3. PEI hollow fiber membrane morphology.

\subsection{PEG and polyzwitterion grafting}

The contact angle is an indicative parameter to verify the formation of hydrogels on membrane surfaces, since they are highly hydrophilic. Table 1 shows the contact angles of the fibers before and after surface functionalization. The unmodified PEI hollow fiber membranes had a contact angle of $88.9^{\circ}$. By grafting either PEG or polyzwitterion on the membrane surface, the contact angle decreased to $\sim 68^{\circ}$, which implies a significant increase in surface hydrophilicity. There is no significant difference between PEG and polyzwitterion layers. 
Table 1 presents the grafting density of the PEG and polyzwitterion layers. The PEG layer has much higher density than the polyzwitterion layer. This might be attributed to the high molecular weight of $\mathrm{NH}_{2}$-PEG used in this study $(5,000 \mathrm{Da})$. The long polymer chains can lead to a higher density if well arranged on the surface.

Table 1. Contact angles of the hollow fiber membranes before and after grafting

\begin{tabular}{lll}
\hline Grafting & Contact angle $\left(^{\mathbf{0}}\right)$ & Grafting density $\left(\boldsymbol{\mu g} / \mathbf{c m}^{\mathbf{2}}\right)$ \\
\hline No & 88.9 & - \\
PEG & 67.9 & $254 \pm 21$ \\
Polyzwitterion & 68.0 & $115 \pm 23$ \\
\hline
\end{tabular}

Figure 4 depicts the FTIR spectra of analogous PEI flat-sheet membranes before and after surface modification. Polyetherimide has characteristic peaks at 1781 and $1736 \mathrm{~cm}^{-1}$, corresponding to the asymmetric and symmetric stretching vibrations of $\mathrm{C}=\mathrm{O}$ in imide groups. The peak at $1356 \mathrm{~cm}^{-1}$ is assigned to the bond stretching vibration of $\mathrm{C}-\mathrm{N}$ in phthalimide rings. Vibrations from 1275 to $1017 \mathrm{~cm}^{-1}$ are attributed to aryl ether bonds. These results are consistent with the FTIR data previously reported for PEI ${ }^{52-53}$. After grafting with PEG, several new peaks appear. The peak at $1158 \mathrm{~cm}^{-1}$ corresponds to the $\mathrm{C}-\mathrm{O}-\mathrm{C}$ ether stretch while the bands peaking at $2850-3000 \mathrm{~cm}^{-1}$ are assigned to the $-\mathrm{CH}_{2}-$ stretching vibrations ${ }^{54}$. The existence of these peaks also confirms the grafting success. The grafted layer is expected to be thin. The penetration depth of the infrared light in ATR measurements, as calculated by Eq. (1), varies from around $0.7 \mu \mathrm{m}$ (at the wavelength of $4000 \mathrm{~cm}^{-1}$ ) to $2.8 \mu \mathrm{m}$ (at the wavelength of $1000 \mathrm{~cm}^{-1}$ ) and the presence of PEI peaks is consistent with the small thickness of the grafted PEG layer. On the other hand, no obvious difference in the IR spectra was observed after modification with 
polyzwitterion layer. This may be due to the formation of an ultrathin layer of polyzwitterion or/and the overlap of its characteristic peaks $\left(1660 \mathrm{~cm}^{-1}\right.$ for amide, $1040 \mathrm{~cm}^{-1}$ for $\left.\mathrm{SO}_{3}{ }^{-}\right)$with the existent peaks of PEI. However, the success of polyzwitterion grafting on PEI surfaces was verified by the surface elemental analyses through X-ray photoelectron spectroscopy (XPS) in our previous work ${ }^{28}$.

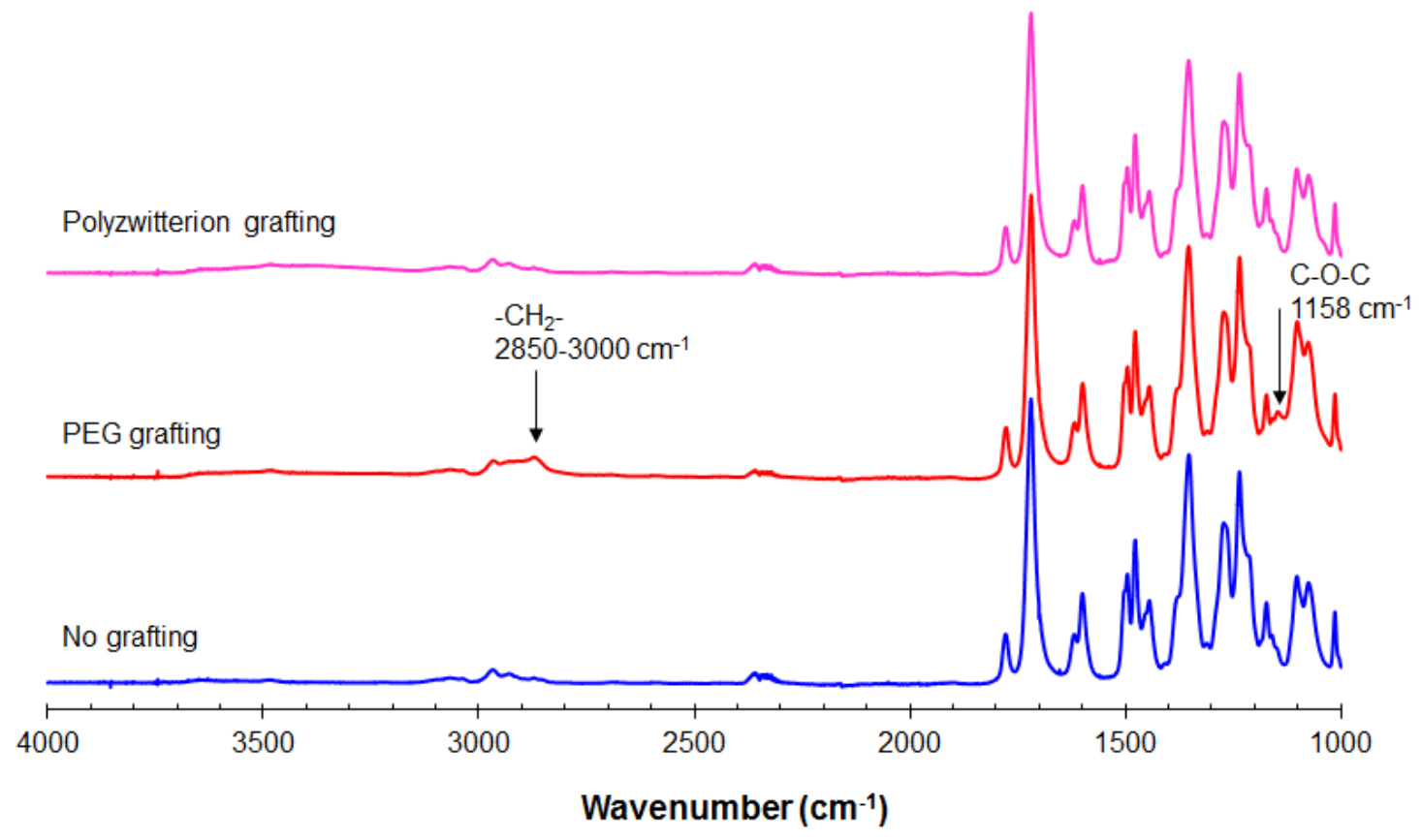

Figure 4. ATR-FITR spectra of the analogous PEI flat-sheet membrane before and after grafting with PEG and polyzwitterion.

\subsection{Ultrafiltration performance}

Table 2 presents the pure water permeance and protein rejection of the hollow fiber membranes before and after grafting with PEG or polyzwitterion. The hydrogels increase the surface hydrophilicity, but as shown in Table 2, the total water permeance is reduced by $15 \%$ and $28 \%$ after grafting with PEG and polyzwitterion layers, respectively. The results for polyzwitterion 
layers are different from those of our previous work, in which grafting was done on the porous support of the membranes with much larger pores. In that case no significant difference in water permeance was observed after grafting with polyzwitterion ${ }^{28}$. This implies that the added resistance to permeation, caused by the thin hydrogel layer, depends on the morphology of the substrate, where grafting is initiated. If the pores are large, practically no difference is observed. If pores are already small, the grafting will significantly affect the permeance. Moreover, it is well known from other reports in literature that hydrogel-based antifouling layers on the selective surface of ultrafiltration membranes can change their barrier properties ${ }^{29,48-49,55}$.

The effect of hydrogel grafting on the ultrafiltration performance was evaluated by measuring the rejection of proteins with different molecular weights. Both unmodified and modified membranes virtually reject $\gamma$-globulin quantitatively. This could be related to the MWCO of the pristine membrane $(67 \mathrm{kDa})$ which is much smaller than the size of the protein $(155-160 \mathrm{kDa})$. Interestingly, grafting PEG reduces the rejection of BSA with the molecular weight of $\sim 66 \mathrm{kDa}$. The pristine PEI membrane rejects $>98 \%$ BSA. One would consider protein fouling during ultrafiltration (will be further analyzed in Sections 3.4 and 3.5); this could lead in case of the unmodified PEI membrane to stronger hindrance toward protein sieving due to reduction of barrier pore size and electrostatic repulsion between the adsorbed protein and protein in solution. On the other hand, grafting the polyzwitterion slightly increases BSA rejection. The different effect on rejection caused by the grafted PEG and polyzwitterion layer may be attributed also to their architectures. As indicated in Figure 1, PEG is grafted to the polydopamine interlayer as linear and flexible chains, while the polyzwitterion forms a crosslinked network. The barrier produced by the linear PEG polymer chains is more dynamic and loose and protein molecules can more easily thread their way through. On contrary, the network of the polyzwitterion, 
generated via in situ polymerization by the aid of the crosslinker monomer MBAA, produces an additional sieving barrier to protein permeation. A significant influence of the cross-linker monomer fraction on the sieving properties of grafted hydrogel layers on polyethersulfone ultrafiltration membranes, i.e. a higher cross-linking degree leads to a lower MWCO, had been found before ${ }^{55}$.

To subtract the possible effect of electrostatic repulsion and to evaluate the effect of the hydrogel layers of protein sieving, a smaller protein with isoelectric point at $\mathrm{pH} 7$, i.e. myoglobin, was used for filtration tests. Table 2 shows that the pristine PEI membrane with an MWCO of $67 \mathrm{kDa}$ can reject myoglobin with its molecular weight of $\sim 17 \mathrm{kDa}$ by only $\sim 38 \%$. Grafting PEG slightly increases its rejection to $\sim 48 \%$ while a doubled rejection is obtained for the polyzwitterion grafted membrane. These results strongly support the argument regarding the important influence of layer architecture, based on the linear structure of the grafted PEG and the crosslinked polyzwitterion network. In addition, the hydration layer, produced by PEG and polyzwitterion chains, plays an important role in repelling protein molecules away. This will be further discussed in Sections 3.4 and 3.5.

Table 2. Pure water permeance and protein rejection of membranes before and after grafting.

\begin{tabular}{llllll}
\hline Grafting & $\begin{array}{l}\text { Water } \\
\text { permeance } \\
\left(\mathbf{L . m}^{-2} \mathbf{h}^{-\mathbf{1}} \cdot \mathbf{b a r}^{-\mathbf{1}}\right)\end{array}$ & $\begin{array}{l}\text { Water flux } \\
\text { reduction by } \\
\text { grafting (\%) }\end{array}$ & $\begin{array}{l}\boldsymbol{\gamma} \text {-Globulin } \\
\text { rejection } \\
(\boldsymbol{\%})\end{array}$ & $\begin{array}{l}\text { BSA } \\
\text { rejection } \\
(\boldsymbol{\%})\end{array}$ & $\begin{array}{l}\text { Myoglobin } \\
\text { rejection } \\
(\boldsymbol{\%})\end{array}$ \\
\hline No grafting & 368 & - & 100 & 98 & 38 \\
PEG & 312 & 15 & 100 & 95 & 48 \\
Poly(zwitterion) & 264 & 28 & 100 & 99 & 80 \\
\hline
\end{tabular}

\subsection{Protein adsorption}


To evaluate the resistance of the membrane surface to protein adsorption, fluorescene-labeled bovine serum albumin (BSA) was employed as foulant, and its surface absorption was observed by fluorescence microscopy. Figure 5a shows that the hydrogel anchored surfaces have much less fluorescent images than the pristine PEI surface, indicating much less protein adsorbed on their surfaces. The strong protein adsorption of the PEI surface is attributed to the hydrophobichydrophobic interaction between the hydrophobic segments of PEI polymer chains (as proven by its contact angle of $89^{\circ}$ ) and protein molecules. In addition, the deposition of amphiphilic biomolecules such as proteins on the hydrophobic PEI surface is also thermodynamically favored, because this process tunes the surface from hydrophobic to hydrophilic to a certain extent and hence minimizes the interfacial energy between the surface and water. The release of clustered water from the hydrophobic surface can provide another (mainly entropic) driving force ${ }^{19-20,56}$. Grafting hydrogels on the PEI membrane increases the resistance to protein fouling, because of the formation of the hydration layer. This layer acts as a barrier to prevent the direct contact of protein molecules with the PEI surface. In this way the initiation of firm bonds, which boosts irreversible fouling, is efficiently minimized.

Figure $5 \mathrm{~b}$ provides the relative protein density on membrane surfaces, by evaluating their relative fluorescent intensity. Grafting PEG and polyzwitterion significantly reduces the fluorescent intensity to $23 \%$ and $11 \%$, respectively. The lower protein adsorption of the polyzwitterion grafted surface is ascribed to the specific character of zwitterionic groups and the crosslinked architecture. The water molecules are bound to a zwitterionic sulfobetaine unit, consisting of a positively charged group $\left(\mathrm{N}^{+}\left(\mathrm{CH}_{3}\right)_{3}\right)$ and a negatively charged group $\left(\mathrm{SO}_{3}{ }^{-}\right)$, at a much higher extent and with less direction sensitivity than those adsorbed on ethylene glycol units of PEG as illustrated in Figure $2 S^{57}$. This combined effect leads to a higher water amount in the hydration 
layer formed on polyzwitterion. Moreover, the water molecules are bound to polyzwitterion more tightly due to a combination of hydrogen bonds and electrostatic forces. As a result, this hydration layer is stronger and more stable, being able to repel protein more efficiently. In addition, once the protein molecules pass through the hydration layer, in the case of PEG, in analogy to what was observed in the ultrafiltration experiments (cf. Table 2), they could more easily move through the hydrogel layer to reach the solid membrane surface and potentially be adsorbed. On contrary, even if they can penetrate the hydration layer of the polyzwitterion anchored surface, the uniformity of charge distribution over the surface at a nanometric scale because of two opposite charge moieties present in the same monomer unit with a balanced charge, a critical factor fostering nonfouling property of zwitterionic poly(sulfobetaine), minimizes their charge interaction. At the same time, the sieving effect of its crosslinked network might also promote protein repellence backward to the solution. Note that between the two hydrogels, rejection for (unlabeled) BSA in ultrafiltration was significantly higher for polyzwitterion compared to PEG grafted membranes (cf. Table 2). As a result, the protein amount remaining on the surface is even less for polyzwitterionic protective layers. 
a)

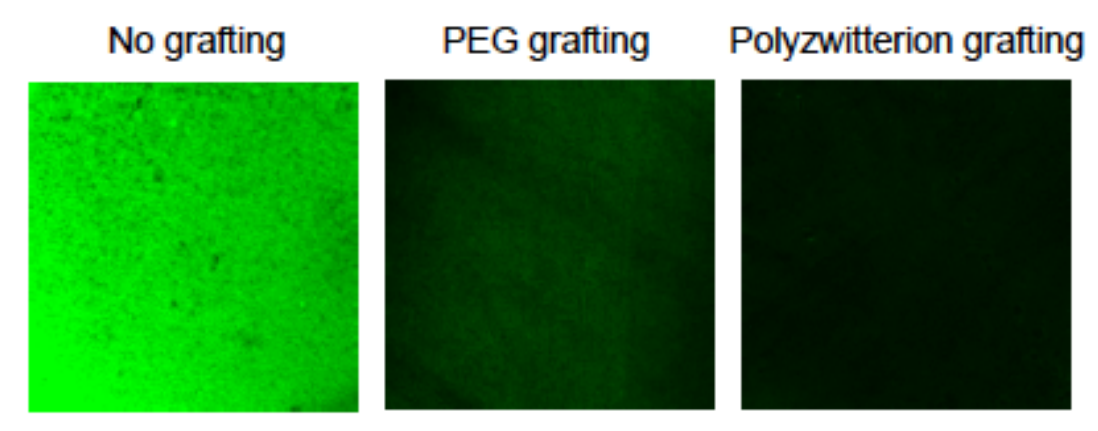

b)

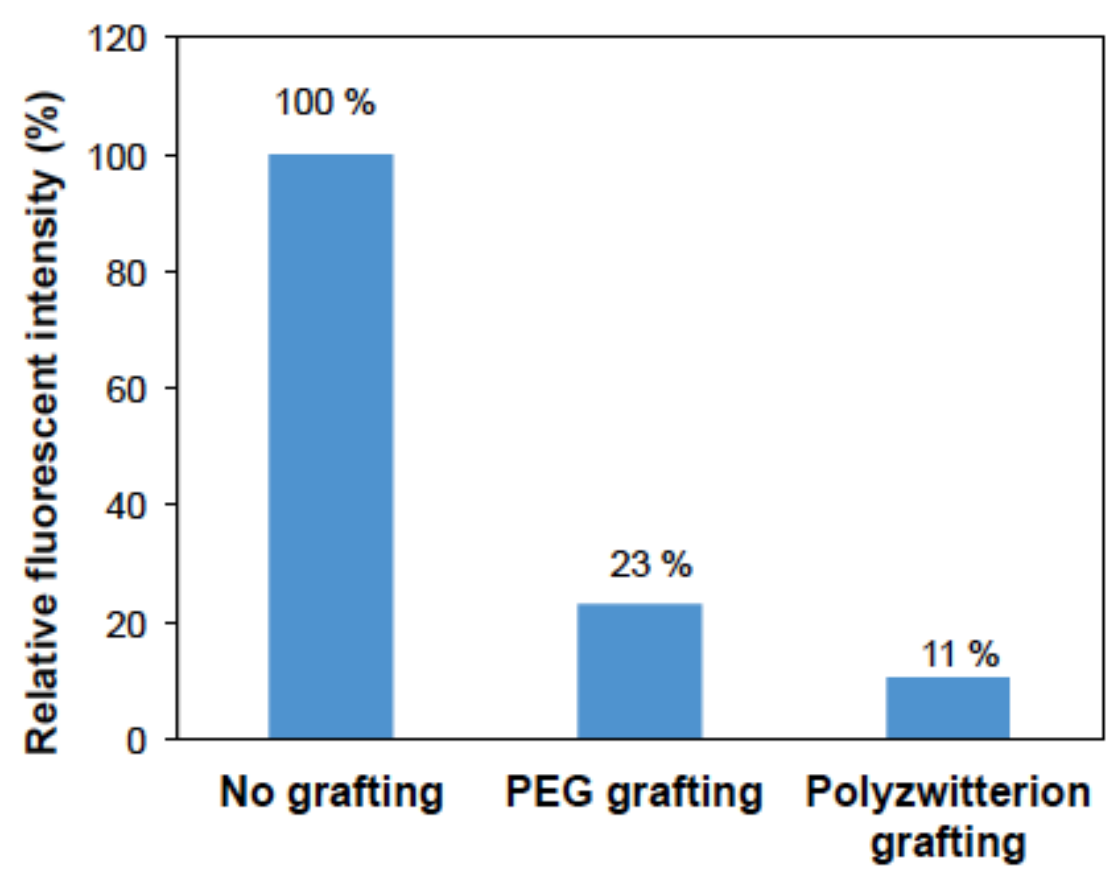

Figure 5. (a) Fluorescence microscopic images and (b) respective relative fluorescence intensities of the analogous flat-sheet membranes after exposure to $0.35 \mathrm{mg} / \mathrm{ml}$ BSA-FITC solution for $1 \mathrm{~h}$.

\subsection{Protein fouling during ultrafiltration}

$\gamma$-Globulin with an isoelectric point at $\mathrm{pH} 7$ and a high molecular weight, to be $100 \%$ rejected by the pristine and modified membranes, was used as a model protein to investigate their fouling susceptibility and the extent of the contribution of electrostatic repulsion and sieving barrier. The filtration was operated until no flux change was observed and the accumulated permeate volume 
reached $90 \mathrm{~L} / \mathrm{m}^{2}$. Flux decline is an undesirable but generally inevitable characteristic of membrane filtration processes. Table 3 shows the relative flux reduction ratio calculated by Eq. (4), comparing the protein filtration flux with the corresponding pure water flux. The pristine PEI membrane has a very high relative flux reduction ratio of $82 \%$. Concentration polarization due to quantitative protein rejection and chosen initial flux is one reason. Severe protein fouling will also contribute; the protein adsorption on the surface or onto the pores partially blocks the permeation pathway of water and hence reduces the flux. In addition, once protein molecules are adsorbed on the surface, the protein-protein interactions may lead to the formation of tighter foulant layer and ultimately also to a cake layer.

Table 3. Membrane fluxes calculated at the normalized accumulative permeate volume of 90 $\mathrm{L} / \mathrm{m}^{2}$ of ultrafiltration with a $500 \mathrm{ppm} \gamma$-globulin solution and flux recovery after washing with water.

\begin{tabular}{llll}
\hline Grafting & $\begin{array}{l}\text { Relative flux } \\
\text { reduction ratio }(\%)\end{array}$ & $\begin{array}{l}\text { Flux recovery } \\
\text { ratio (\%) }\end{array}$ & $\begin{array}{l}\text { Relative flux } \\
\text { enhancement (\%) }\end{array}$ \\
\hline No grafting & $82 \pm 2$ & $42 \pm 4$ & 0 \\
PEG & $61 \pm 6$ & $63 \pm 5$ & $41 \pm 21$ \\
Polyzwitterion & $55 \pm 2$ & $94 \pm 4$ & $69 \pm 21$ \\
\hline
\end{tabular}

Although PEG and polyzwitterion grafted surfaces have much smaller protein adsorption than the pristine PEI surface as shown in Figure 5, Table 3 illustrates that their flux still suffers up to $61 \%$ and $55 \%$ reduction, respectively. This can be explained by the large difference of protein adsorption under static and convective conditions. In the static environment, protein molecules approach the surface by diffusion and the attraction and/or repulsion force play important roles in their adsorption. The adsorption mainly occurs on the surface. In the dynamic ultrafiltration 
process, protein molecules are driven to the membrane surface by the fluid flow under a hydraulic pressure and hence may not only deposit on the membrane surface but also be entrapped in the membrane pores. As mentioned above, concentration polarization is also inevitable. Therefore, flux reduction and membrane fouling still happen during dynamic ultrafiltration.

Although grafting PEG and polyzwitterion layers reduces the pure water flux, it brings advantages concerning the resistance to fouling. As aforementioned, the hydration layer produced by hydrogels excludes foulants from close contact with the solid surface, hindering the establishment of strong bonds, which promotes adsorption or irreversible fouling. In addition, when protein molecules approach the surface under hydraulic pressure, the repulsive elastic forces generated by compression of the hydration layer and the osmotic stress created by the escape of water molecules out of the hydrated hydrogel layer during the compression drive them away from the surface. The stability of the hydration layer under compression determines the degree of protein repellence. Since the polyzwitterion layer produces a stronger hydration layer, fouling is less and the relative flux reduction ratio is smaller.

After operation, the membranes were flushed with water under no hydraulic pressure and pure water flux was re-measured to calculate the flux recovery ratio by using Eq. (5). The flux recovery ratio reflects the reversibility of fouling. Irreversible fouling is undesirable because it requires chemical cleaning, which may affect membrane life and pose a problem related to the disposal of spent chemical reagents. Table 3 illustrates that the pristine PEI membrane recovers $42 \%$ of its original flux. The cleaning process relieves protein molecules adsorbed on the surface or accumulated within the porous substrate. When hydraulic pressure is re-applied, the sudden pressurization may generate an impulsion and wash away loosely bound foulants. Therefore, the 
water flux is recovered to a certain extent, which reflects a partial reversibility of fouling. On the other hand, the tight bonds of certain protein molecules cannot be released by the hydraulic cleaning, which represents the fraction of irreversible fouling. Since PEI is hydrophobic (as verified by its contact angle in Table 1), the density fluctuation of its surrounding water is high and its surface cavity formation (i.e. formation of area not occupied by water) is easy ${ }^{58}$, or clustered water is associated with the surface ${ }^{19-20,55}$. These factors suggest highly favorable replacement of surface water by amphiphilic protein molecules when they approach the surface. This replacement is virtually accompanied by the removal of the hydration layer of extremely hydrated protein molecules ${ }^{59}$. The loss of surface bound water induces conformational changes in the proteins, which leads to the direct contact and interaction of the hydrophobic part of the proteins with that of the membrane surface. This was reported as the reason of irreversible fouling of solid surfaces by proteins ${ }^{60}$.

Table 3 also shows that grafting hydrogel layers increases fouling reversibility; especially the polyzwitterion grafted membrane can achieve $94 \%$ flux recovery. Rather than the highly fluctuating and cavity-containing water layer on the PEI hydrophobic surface, the hydration layer of hydrophilic hydrogels has high fraction of water molecules bound by stronger hydrogen bonding or electrostatic forces (in the case of polyzwitterion). It was reported that the structure of water surrounding protein molecules and membrane surfaces affects the protein adsorption ${ }^{10,60-}$ 61. When the water state at the membrane surface is similar to that in a solution or its free water fraction is high, protein molecules do not need to release bound water molecules even if they contact with the surface. Hence the hydrophobic interaction between protein molecules and the membrane surface does not occur. As a result, their conformational change during adsorption is suppressed and the irreversible adsorption would be efficiently reduced. It is worth to note that 
the hydration layer formed in hydrogels in fact has a two-layered structure of bound and unbound water molecules. The primary bound water layer is first formed, consisting of water molecules directly attached with hydrophilic polymer chains, while the secondary unbound layer is produced by the interaction between free water molecules in solution and bound surface water after the primary layer is well established. While the polyzwitterion produces a more tightly bound water layer because of its unique electrostatic forces, its unbound water molecules are more mobile and behave more like free water than those of $\mathrm{PEG}^{57}$. As a result, the conformational changes in protein are more likely to occur in the case of PEG. In addition, the linearity of its polymer chains offers protein molecules a high probability of approaching the solid surface, worsening their conformational changes and inducing irreversible adsorption. Consequently, its fraction of irreversible fouling is still high, while the fouling of the polyzwitterion grafted membrane is completely reversible.

The relative flux enhancement was calculated by Eq. (6) to compare the flux of the unmodified and modified membranes after hydraulic cleaning. Although the pristine membrane has a higher initial pure water flux than the hydrogel-grafted membranes as shown in Table 2, its flux is deteriorated by protein fouling, especially irreversible fouling. After cleaning, the water fluxes of PEG and polyzwitterion grafted membranes are $41 \%$ and $69 \%$ higher than that of the pristine membrane, respectively. In addition, the hydrogel-grafted membranes have significantly higher solute rejection than the pristine one (cf. Table 2), leaving even more room for further improvement of overall ultrafiltration process performance by tailored thin-layer hydrogel composite membranes.

3.6. Stability in the presence of cleaning chemicals 
The stability of the hydrogel layer is an important feature from the application point of view, because frequent chemical cleaning may be required for membrane-based process plants. In this study, their stability in different cleaning solutions including acid $(\mathrm{pH} 2)$, base $(\mathrm{pH} 12)$ and chlorine ( $500 \mathrm{ppm})$ was evaluated through membrane water flux changes (Figure 6) and alterations in their chemical structures (Figures 3S). The pristine PEI membrane shows virtually no flux changes after immersion in acid or base, during the test period of 6 days, which is consistent with no changes in characteristic peaks of FTIR spectra. These results confirm the stability of PEI in moderate acid and base. As compared to other polyimides, PEI is stable in moderate base conditions ${ }^{62}$ (such as $\mathrm{pH} 12$ in this study) probably due to their ether segments. Figure 6 shows that the permeance of PEI membrane increases about $50 \%$ after soaking it in the chlorine solution for 6 days. Interestingly, its corresponding FTIR spectrum does not indicate chemical changes. Indeed, PEI was reported to be stable in bleaching solutions ${ }^{62}$. The permeation change is attributed to the remarkable release of ethylene glycol compounds from the membrane. In this study, the PEI hollow fiber membrane was fabricated with diethylene glycol as additive in the polymer dope solution and ethylene glycol as bore fluid for hollow fiber spinning. To evaluate whether the removal of ethylene glycol affects the rejection of membranes, we measured the myoglobin rejection. The results in Table $3 \mathrm{~S}$ show that there is no significant effect. Their high viscosity (34 and $20 \mathrm{cP}$, respectively ${ }^{63}$ ) and the configuration of hollow fiber limit their diffusion out of the membrane, even though it was washed in water for a long period of 3 days and subsequently kept in water. The exposure to chlorine leads to the chlorination and/or oxidation of these ethylene glycol compounds to produce simple final products (e.g. $\mathrm{HCl}$, $\mathrm{CO}_{2}$ and $\mathrm{CO}$ ) which can easily be washed out of the membrane. As a result, its pores are vacated 
for water permeation, leading to higher flux. Hence, chlorine treatment is an effective approach to remove these ethylene glycol compounds from membranes.

Also as indicated in Figure 6, the flux changes of the pristine and polyzwitterion grafted membranes are identical, which may suggest that the polyzwitterion layer is stable in these chemicals and its observed flux changes (if any) are attributed to the changes in the PEI substrate membrane. It should be noted that IR analysis is not possible here since no specific peaks could be detected for the polyzwitterion layer on PEI (cf. Figure 4).

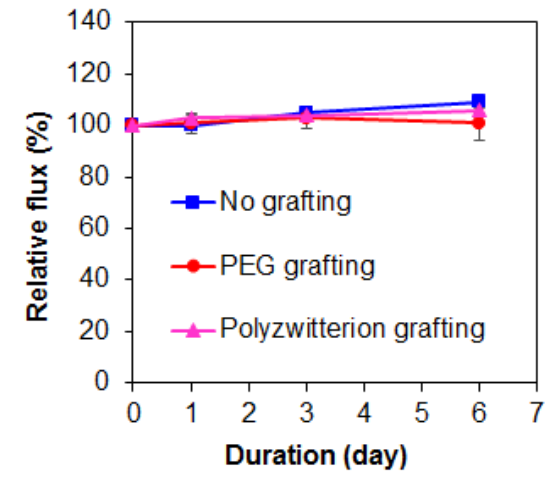

a)

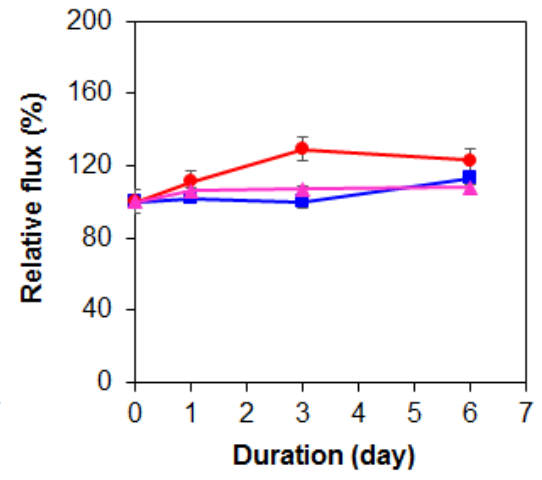

b)

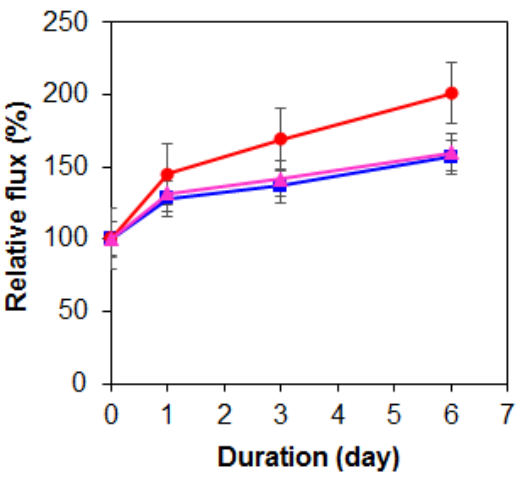

c)

Figure 6. Membrane flux changes after soaking into (a) $\mathrm{pH} \mathrm{2;} \mathrm{(b)} \mathrm{pH} 12$ and (c) 500 ppm chlorine solutions.

Figure 6 also denotes that the PEG-grafted membrane has no significant water permeance change when soaked in acid, but $\sim 25 \%$ and $\sim 130 \%$ permeance increases if soaked in base and chlorine solutions, respectively. Figure 3S indicates that the intensity of PEG characteristic peaks reduces after alkaline treatment and these peaks completely disappear after chlorine treatment. The extensive exposure to base may lead to alkaline hydrolysis of imine bonds between the PEG chains and the dopamine-grafted PEI membrane (cf. Figure 1), followed by release of PEG chains from the membrane surface. Meanwhile, chlorine treatment is expected to cause oxidation 
and/or chlorination of the PEG layer. These processes degrade PEG chains to form simple products, which would be easily unattached. After the PEG chains are removed, the further oxidation of the dopamine layer may occur and affect the surface pore size, which contributes to higher water flux increment of the PEG-grafted membrane than that of the pristine membrane.

\section{Conclusions}

In this study, PEG and zwitterionic poly(sulfobetaine) hydrogel layers were grafted on PEI ultrafitration membranes and their filtration properties were explored. The fouling resistance of the pristine and modified membranes was investigated in-depth and their stability in cleaning chemicals was evaluated. The following conclusions can be drawn based on this work:

(1) The PEG chains can be successfully grafted on the PEI membrane surface using dopamine as the intermediate layer.

(2) Depending on the grafting location and barrier pore structure and pore size of the membrane, grafting hydrogels on the membrane surface may lead to water flux decline, but this may be accompanied by reduced sieving of macromolecular solutes.

(3) The 3D architecture of hydrogels affects solute rejection. In particular, the end-on grafted linear chains of PEG do not significantly contribute to protein rejection, while the crosslinked network of poly(sulfobetaine) provides an pronounced additional sieving effect.

(4) The strength of the hydration layer formed by hydrogels and the state of their unbound water molecules determine the protein adsorption or fouling behavior. The strong hydration layer of the poly(sulfobetaine) hydrogel formed by both hydrogen bonding and electrostatic forces and the their highly mobile unbound water molecules promote 
reversible fouling and lead to $98 \%$ flux recovery of the resultant membrane (observed after ultafiltration of a completely rejected protein and simple hydraulic cleaning).

(5) The attachment of long-chained PEG onto the membrane surface via their terminal amino groups may not be a sufficient approach, because the resultant bonds may be susceptible to alkaline hydrolysis during membrane cleaning. Regardless to grafting methods, however, PEG itself is not stable in chlorine solutions.

(6) The zwitterionic hydrogel is better than end-on grafted PEG for surface modification of ultrafiltration membranes in terms of filtration performance, fouling behavior and stability.

Supporting Information. The SEM image of the membrane surface, FTIR characterization before and after treatments in different $\mathrm{pH}$ and chlorine solutions and spinning conditions are presented as supporting information.

\section{Acknowledgements}

The work was supported by King Abdullah University of Science and Technology (KAUST). MU acknowledges financial support for the work by the German Federal Ministry of Education and Research (BMBF grant 02WA1261A).

\section{References}

(1) Koehler, J. A.; Ulbricht, M.; Belfort, G. Intermolecular forces between a protein and a hydrophilic modified polysulfone film with relevance to filtration. Langmuir 2000, 16 (26), 10419-10427.

(2) Ye, Y.; Le Clech, P.; Chen, V.; Fane, A. Evolution of fouling during crossflow filtration of model EPS solutions. J. Membr. Sci. 2005, 264 (1), 190-199. 
(3) Maartens, A.; Swart, P.; Jacobs, E. Removal of natural organic matter by ultrafiltration: characterisation, fouling and cleaning. Water Sci. Technol. 1999, 40 (9), 113-120.

(4) Lee, N.; Amy, G.; Croué, J.P.; Buisson, H. Morphological analyses of natural organic matter (NOM) fouling of low-pressure membranes (MF/UF). J. Membr. Sci. 2005, 261 (1), 7-16.

(5) Gray, S. R.; Ritchie, C.; Tran, T.; Bolto, B. Effect of NOM characteristics and membrane type on microfiltration performance. Water Res. 2007, 41 (17), 3833-3841.

(6) Kang, G. D.; Cao, Y. M. Development of antifouling reverse osmosis membranes for water treatment: a review. Water Res. 2012, 46 (3), 584-600.

(7) Yang, Q.; Adrus, N.; Tomicki, F.; Ulbricht, M. Composites of functional polymeric hydrogels and porous membranes. J. Mater. Chem. 2011, 21 (9), 2783-2811.

(8) Jeon, S.; Lee, J.; Andrade, J.; De Gennes, P. Protein-surface interactions in the presence of polyethylene oxide: I. Simplified theory. J. Colloid Interface Sci. 1991, 142 (1), 149-158.

(9) Chapman, R. G.; Ostuni, E.; Takayama, S.; Holmlin, R. E.; Yan, L.; Whitesides, G. M. Surveying for surfaces that resist the adsorption of proteins. J. Am. Chem. Soc. 2000, 122 (34), 8303-8304.

(10) Holmlin, R. E.; Chen, X.; Chapman, R. G.; Takayama, S.; Whitesides, G. M. Zwitterionic SAMs that resist nonspecific adsorption of protein from aqueous buffer. Langmuir 2001, 17 (9), 2841-2850.

(11) Jeon, S.; Andrade, J. Protein-surface interactions in the presence of polyethylene oxide: II. Effect of protein size. J. Colloid Interface Sci. 1991, 142 (1), 159-166. 
(12) Harder, P.; Grunze, M.; Dahint, R.; Whitesides, G.; Laibinis, P. Molecular conformation in oligo (ethylene glycol)-terminated self-assembled monolayers on gold and silver surfaces determines their ability to resist protein adsorption. J. Phys. Chem. B 1998, 102 (2), 426-436.

(13) Llanos, G. R.; Sefton, M. V. Review: Does polyethylene oxide possess a low thrombogenicity? J. Biomater. Sci., Polym. Ed. 1993, 4 (4), 381-400.

(14) Shen, M.; Martinson, L.; Wagner, M. S.; Castner, D. G.; Ratner, B. D.; Horbett, T. A. PEO-like plasma polymerized tetraglyme surface interactions with leukocytes and proteins: in vitro and in vivo studies. J. Biomater. Sci., Polym. Ed. 2002, 13 (4), 367-390.

(15) Ostuni, E.; Chapman, R. G.; Holmlin, R. E.; Takayama, S.; Whitesides, G. M. A survey of structure-property relationships of surfaces that resist the adsorption of protein. Langmuir 2001, 17 (18), 5605-5620.

(16) Cheng, G.; Zhang, Z.; Chen, S.; Bryers, J. D.; Jiang, S. Inhibition of bacterial adhesion and biofilm formation on zwitterionic surfaces. Biomaterials 2007, 28 (29), 4192-4199.

(17) Liu, X.; Xu, Y.; Wu, Z.; Chen, H. Poly (N-vinylpyrrolidone)-modified surfaces for biomedical applications. Macromol. Biosci. 2013, 13 (2), 147-154.

(18) Friebe, A.; Ulbricht, M. Cylindrical pores responding to two different stimuli via surfaceinitiated atom transfer radical polymerization for synthesis of grafted diblock copolymers. Macromolecules 2009, 42 (6), 1838-1848.

(19) Ulbricht, M.; Yang, H. Porous polypropylene membranes with different carboxyl polymer brush layers for reversible protein binding via surface-initiated graft copolymerization. Chem. Mater. 2005, 17 (10), 2622-2631. 
(20) Piletsky, S. A.; Matuschewski, H.; Schedler, U.; Wilpert, A.; Piletska, E. V.; Thiele, T. A.; Ulbricht, M. Surface functionalization of porous polypropylene membranes with molecularly imprinted polymers by photograft copolymerization in water. Macromolecules 2000, 33 (8), 3092-3098.

(21) Sergeyeva, T. A.; Matuschewski, H.; Piletsky, S. A.; Bendig, J.; Schedler, U.; Ulbricht, M. Molecularly imprinted polymer membranes for substance-selective solid-phase extraction from water by surface photo-grafting polymerization. J. Chromatogr. A 2001, 907 (1), 89-99.

(22) Friebe, A.; Ulbricht, M. Controlled pore functionalization of poly (ethylene terephthalate) track-etched membranes via surface-initiated atom transfer radical polymerization. Langmuir 2007, 23 (20), 10316-10322.

(23) Hower, J. C.; Bernards, M. T.; Chen, S.; Tsao, H. K.; Sheng, Y. J.; Jiang, S. Hydration of “nonfouling” functional groups. J. Phys. Chem. B 2008, 113 (1), 197-201.

(24) Shao, Q.; He, Y.; White, A. D.; Jiang, S. Difference in hydration between carboxybetaine and sulfobetaine. J. Phys. Chem. B 2010, 114 (49), 16625-16631.

(25) Chang, Y.; Chen, S.; Yu, Q.; Zhang, Z.; Bernards, M.; Jiang, S. Development of biocompatible interpenetrating polymer networks containing a sulfobetaine-based polymer and a segmented polyurethane for protein resistance. Biomacromolecules 2007, 8 (1), 122-127.

(26) Chen, S.; Zheng, J.; Li, L.; Jiang, S. Strong resistance of phosphorylcholine selfassembled monolayers to protein adsorption: insights into nonfouling properties of zwitterionic materials. J. Am. Chem. Soc. 2005, 127 (41), 14473-14478. 
(27) Eshet, I.; Freger, V.; Kasher, R.; Herzberg, M.; Lei, J.; Ulbricht, M. Chemical and physical factors in design of antibiofouling polymer coatings. Biomacromolecules 2011, 12 (7), 2681-2685.

(28) Le, N. L.; Quilitzsch, M.; Cheng, H.; Hong, P. Y.; Ulbricht, M.; Nunes, S. P.; Chung, T. S. Hollow fiber membrane lumen modified by polyzwitterionic grafting. J. Membr. Sci. 2017, $522,1-11$

(29) Quilitzsch, M.; Osmond, R.; Krug, M.; Heijnen, M.; Ulbricht, M. Macro-initiator mediated surface selective functionalization of ultrafiltration membranes with anti-fouling hydrogel layers applicable to ready-to-use capillary membrane modules. J. Membr. Sci. 2016, $518,328-337$.

(30) Zhang, Z.; Chen, S.; Chang, Y.; Jiang, S. Surface grafted sulfobetaine polymers via atom transfer radical polymerization as superlow fouling coatings. J. Phys. Chem. B 2006, 110 (22), 10799-10804.

(31) Zhang, Z.; Chen, S.; Jiang, S. Dual-functional biomimetic materials: nonfouling poly(carboxybetaine) with active functional groups for protein immobilization. Biomacromolecules 2006, 7 (12), 3311-3315.

(32) Ladd, J.; Zhang, Z.; Chen, S.; Hower, J. C.; Jiang, S. Zwitterionic polymers exhibiting high resistance to nonspecific protein adsorption from human serum and plasma. Biomacromolecules 2008, 9 (5), 1357-1361.

(33) Zhang, Z.; Chao, T.; Chen, S.; Jiang, S. Superlow fouling sulfobetaine and carboxybetaine polymers on glass slides. Langmuir 2006, 22 (24), 10072-10077. 
(34) Feng, W.; Brash, J. L.; Zhu, S. Non-biofouling materials prepared by atom transfer radical polymerization grafting of 2-methacryloloxyethyl phosphorylcholine: separate effects of graft density and chain length on protein repulsion. Biomaterials 2006, 27 (6), 847-855.

(35) Zhou, M.; Liu, H.; Kilduff, J. E.; Langer, R.; Anderson, D. G.; Belfort, G. Highthroughput membrane surface modification to control NOM fouling. Environ. Sci. Technol. 2009, 43 (10), 3865-3871.

(36) Zhao, Y. H.; Wee, K. H.; Bai, R. Highly hydrophilic and low-protein-fouling polypropylene membrane prepared by surface modification with sulfobetaine-based zwitterionic polymer through a combined surface polymerization method. J. Membr. Sci. 2010, 362 (1), 326333.

(37) Chang, Y.; Chang, W.J.; Shih, Y. J.; Wei, T. C.; Hsiue, G. H., Zwitterionic sulfobetainegrafted poly(vinylidene fluoride) membrane with highly effective blood compatibility via atmospheric plasma-induced surface copolymerization. ACS Appl. Mater. Interfaces 2011, 3 (4), 1228-1237.

(38) Hadidi, M.; Zydney, A. L. Fouling behavior of zwitterionic membranes: Impact of electrostatic and hydrophobic interactions. J. Membr. Sci. 2014, 452, 97-103.

(39) Liu, P. S.; Chen, Q.; Wu, S. S.; Shen, J.; Lin, S. C. Surface modification of cellulose membranes with zwitterionic polymers for resistance to protein adsorption and platelet adhesion. J. Membr. Sci. 2010, 350 (1), 387-394. 
(40) Yang, Y. F.; Li, Y.; Li, Q. L.; Wan, L. S.; Xu, Z. K. Surface hydrophilization of microporous polypropylene membrane by grafting zwitterionic polymer for anti-biofouling. $J$. Membr. Sci. 2010, 362 (1), 255-264.

(41) Meng, H.; Cheng, Q.; Li, C., Polyacrylonitrile-based zwitterionic ultrafiltration membrane with improved anti-protein-fouling capacity. Appl. Surf. Sci. 2014, 303, 399-405.

(42) Zhao, J.; Shi, Q.; Luan, S.; Song, L.; Yang, H.; Shi, H.; Jin, J.; Li, X.; Yin, J.; Stagnaro, P. Improved biocompatibility and antifouling property of polypropylene non-woven fabric membrane by surface grafting zwitterionic polymer. J. Membr. Sci. 2011, 369 (1), 5-12.

Li, M. Z.; Li, J. H.; Shao, X. S.; Miao, J.; Wang, J. B.; Zhang, Q. Q.; Xu, X. P. Grafting zwitterionic brush on the surface of PVDF membrane using physisorbed free radical grafting technique. J. Membr. Sci. 2012, 405, 141-148.

(44) Zhao, Y. F.; Zhu, L. P.; Yi, Z.; Zhu, B. K.; Xu, Y. Y. Improving the hydrophilicity and fouling-resistance of polysulfone ultrafiltration membranes via surface zwitterionicalization mediated by polysulfone-based triblock copolymer additive. J. Membr. Sci. 2013, 440, 40-47.

(45) Zhao, Y. H.; Zhu, X. Y.; Wee, K. H.; Bai, R. Achieving highly effective non-biofouling performance for polypropylene membranes modified by UV-induced surface graft polymerization of two oppositely charged monomers. J. Phys. Chem. B 2010, 114 (7), 24222429.

(46) Xie, Y.; Li, S. S.; Jiang, X.; Xiang, T.; Wang, R.; Zhao, C. S. Zwitterionic glycosyl modified polyethersulfone membranes with enhanced anti-fouling property and blood compatibility. J. Colloid Interface Sci. 2015, 443, 36-44. 
(47) Liu, Y.; Zhang, S.; Wang, G. The preparation of antifouling ultrafiltration membrane by surface grafting zwitterionic polymer onto poly(arylene ether sulfone) containing hydroxyl groups membrane. Desalination 2013, 316, 127-136.

(48) McCloskey, B. D.; Park, H. B.; Ju, H.; Rowe, B. W.; Miller, D. J.; Chun, B. J.; Kin, K.;

Freeman, B. D. Influence of polydopamine deposition conditions on pure water flux and foulant adhesion resistance of reverse osmosis, ultrafiltration, and microfiltration membranes. Polymer 2010, 51 (15), 3472-3485.

(49) McCloskey, B. D.; Park, H. B.; Ju, H.; Rowe, B. W.; Miller, D. J.; Freeman, B. D. A bioinspired fouling-resistant surface modification for water purification membranes. J. Membr. Sci. 2012, 413, 82-90.

(50) Zuo, J.; Wang, Y.; Chung, T. S. Novel organic-inorganic thin film composite membranes with separation performance surpassing ceramic membranes for isopropanol dehydration. $J$. Membr. Sci. 2013, 433, 60-71.

(51) Kim, D.; Le, N. L.; Nunes, S. P. The effects of a co-solvent on fabrication of cellulose acetate membranes from solutions in 1-ethyl-3-methylimidazolium acetate. J. Membr. Sci. 2016, $520,540-549$.

(52) Vora, R. H.; Goh, S. H.; Chung, T. S. Synthesis and properties of fluoro-polyetherimides. Polym. Eng. Sci. 2000, 40 (6), 1318-1329.

(53) Romero, A. I.; Parentis, M. L.; Habert, A. C.; Gonzo, E. E. Synthesis of polyetherimide/silica hybrid membranes by the sol-gel process: influence of the reaction conditions on the membrane properties. J. Mater. Sci. 2011, 46 (13), 4701-4709. 
(54) Alcantar, N. A.; Aydil, E. S.; Israelachvili, J. N. Polyethylene glycol-coated biocompatible surfaces. J. Biomed. Mater. Res. 2000, 51 (3), 343-351.

(55) Peeva, P. D.; Million, N.; Ulbricht, M. Factors affecting the sieving behavior of antifouling thin-layer cross-linked hydrogel polyethersulfone composite ultrafiltration membranes. $J$. Membr. Sci. 2012, 390, 99-112.

(56) Susanto, H.; Franzka, S.; Ulbricht, M. Dextran fouling of polyethersulfone ultrafiltration membranes-causes, extent and consequences. J. Membr. Sci. 2007, 296 (1), 147-155.

(57) Wu, J.; Lin, W.; Wang, Z.; Chen, S.; Chang, Y. Investigation of the hydration of nonfouling material poly (sulfobetaine methacrylate) by low-field nuclear magnetic resonance. Langmuir 2012, 28 (19), 7436-7441.

(58) Jamadagni, S. N.; Godawat, R.; Garde, S. How surface wettability affects the binding, folding, and dynamics of hydrophobic polymers at interfaces. Langmuir 2009, 25 (22), 1309213099.

(59) Lu, D. R.; Lee, S. J.; Park, K. Calculation of solvation interaction energies for protein adsorption on polymer surfaces. J. Biomater. Sci., Polym. Ed. 1992, 3 (2), 127-147.

(60) Ishihara, K.; Nomura, H.; Mihara, T.; Kurita, K.; Iwasaki, Y.; Nakabayashi, N. Why do phospholipid polymers reduce protein adsorption? J. Biomed. Mater. Res. 1998, 39 (2), 323-330.

(61) Kane, R. S.; Deschatelets, P.; Whitesides, G. M. Kosmotropes form the basis of proteinresistant surfaces. Langmuir 2003, 19 (6), 2388-2391.

(62) Ultem, PEI, Resin product guide, GE Plastics. 1993. 
(63) Smallwood, I., Handbook of organic solvent properties. Butterworth-Heinemann. 2012. 


\section{List of abbreviations and nomenclatures}

\begin{tabular}{|c|c|}
\hline Abbreviations & \\
\hline AIBN & : 2,2'-azobis(2-methylpropionitrile) \\
\hline APS & : ammonium persulfate \\
\hline ATR & : attenuated total reflectance \\
\hline BMA & : butylmethacrylate \\
\hline BSA & : bovine serum albumin \\
\hline BSA-FITC & : fluorescein isothiocynate-conjugated bovine serum albumin \\
\hline DEG & : diethylene glycol \\
\hline DMAEMA-co-BMA & : (2-dimethyl amino) ethyl methacrylate-co-butyl methacrylate) \\
\hline DMAEMA & : 2-(dimethylamino)ethylmethacrylate \\
\hline DMF & : dimethylformamide \\
\hline EG & : ethylene glycol \\
\hline FESEM & : field emission scanning electron microscope \\
\hline FTIR & : fourier transform infrared spectroscopy \\
\hline MBAA & : N,N-methylene bisacrylamide \\
\hline MWCO & : molecular weight cut-off \\
\hline $\mathrm{NH}_{2}-\mathrm{PEG}$ & : methoxypolyethylene glycol amine \\
\hline NMP & : N-methyl-pyrrolidone \\
\hline NMR & : nuclear magnetic resonance \\
\hline PDI & : polydispersity index \\
\hline PEG & : poly(ethylene glycol) \\
\hline PEI & : polyetherimide \\
\hline
\end{tabular}


PWP

SPP

XPS

\section{Nomenclatures}

$A_{m}$

$Q$

$t$

$R$

FR

FRR

$F E$

$c_{p}$

$c_{f}$

$J_{p}$

$J_{w}$

$J_{w 2}$

$J_{m}$

$J_{u m}$

$d_{p}$

$n_{1}$

$n_{2}$

$\lambda$
: pure water permeance

: 3-((3-methacrylamidopropyl)dimethylammonio)propane-1-sulfonate

: X-ray photoelectron spectroscopy

: effective membrane area $\left(\mathrm{m}^{2}\right)$

: water permeation volumetric flow rate $(\mathrm{L} / \mathrm{h})$

: time (s)

: solute rejection $(\%)$

: relative flux reduction $(\%)$

: flux recovery $(\%)$

: flux enhancement $(\%)$

: solute concentration in the permeate (ppm)

: solute concentration in the feed (ppm)

: pure water flux $\left(\mathrm{L} \mathrm{m}^{-2} \mathrm{~h}^{-1}\right)$

: water flux of protein filtration $\left(\mathrm{L} \mathrm{m}^{-2} \mathrm{~h}^{-1}\right)$

: pure water flux after hydraulic cleaning $\left(\mathrm{L} \mathrm{m}^{-2} \mathrm{~h}^{-1}\right)$

: pure water flux of modified membrane after cleaning $\left(\mathrm{L} \mathrm{m}^{-2} \mathrm{~h}^{-1}\right)$

: pure water flux of unmodified membrane after cleaning $\left(\mathrm{L} \mathrm{m}^{-2} \mathrm{~h}^{-1}\right)$

: penetration depth of infrared beam $(\mu \mathrm{m})$

: refractive index of crystal

: refractive index of sample

: wavelength of light $(\mu \mathrm{m})$ 
: angle of incidence of infrared beam

$\triangle P$ : transmembrane pressure drop (bar)

$\Delta v$ : volume (L) 


\section{Table of Contents Graphic}

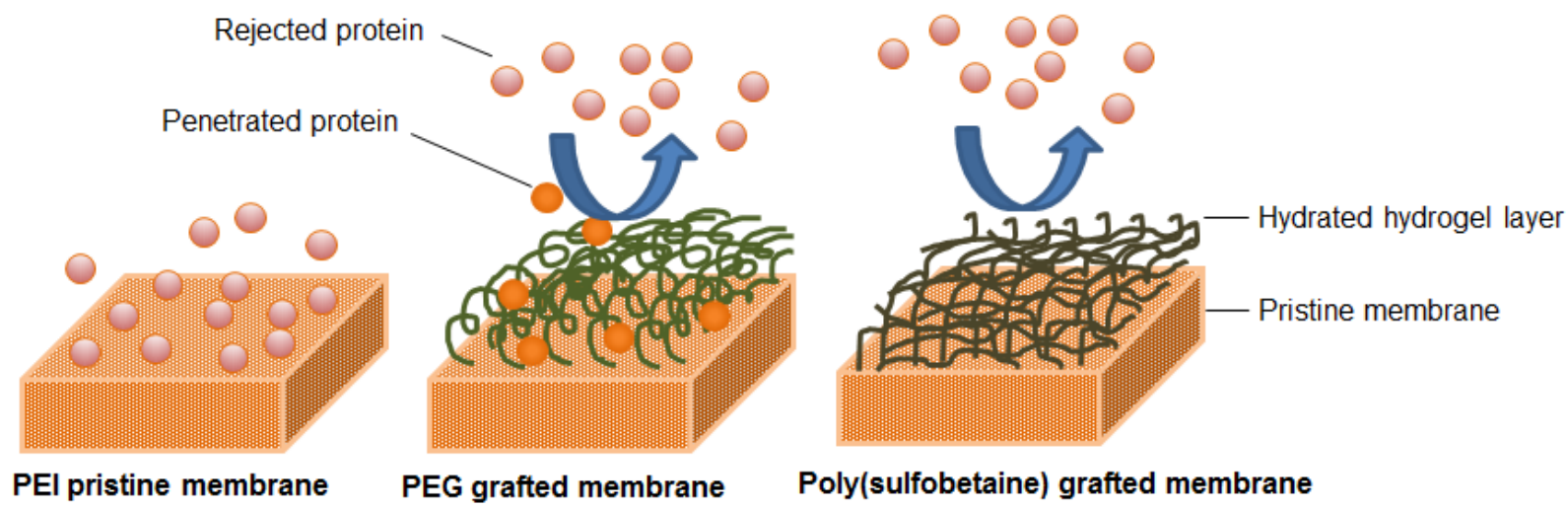

